\title{
The Role of Homer Family Adaptor Proteins in Regulation of Store-Operated Calcium Influx in A431 Cells
}

\author{
M. A. Ryazanceva, A. V. Shalygin, and E. V. Kaznacheyeva \\ Institute of Cytology, Russian Academy of Sciences, St. Petersburg; \\ e-mail:a_shalygin@mail.ru
}

DOI: $10.1134 / \mathrm{S} 199074780903043 \mathrm{X}$

The major pathways for $\mathrm{Ca}^{2+}$ influx in nonexcitable cells are store-operated channels (SOC). SOCs are activated by depletion of intracellular calcium stores. In the previous studies we used patch-clamp electrophysiology to describe the properties of store-operated channels $I_{\min }$ in human carcinoma A431 cell lines. $I_{\min }$ are gated by direct protein-protein interaction with inositol-1,4,5-trisphosphate receptor type $1 \quad\left(\mathrm{IP}_{3} \mathrm{R} 1\right)$. We supposed that this interaction might be facilitated by scaffold proteins of Homer family. Homer family proteins specifically bind to unique PPXXF sequence in $\mathrm{IP}_{3} \mathrm{R}$ and in some other proteins. Several isoforms of Homer proteins exist. Homer 1c isoforms have coilcoiled domain, which mediate homooligomerization. That is why Homer 1c oligomers can form macromolecular complexes with partner proteins. Homer 1a isoform lacking coil-coiled domain can disrupt macromolecular complexes of Homer 1c and its partner proteins. The aim of this study was to determine the role of Homer protein in activation of store-operated channels.

We applied the Gst-Homer recombinant protein (concentration $100 \mathrm{nM}$ ) to inside-out patches excised from A431 cells using $105 \mathrm{mM} \mathrm{Ba}^{2+}$ in the pipette as a current carrier. Application of Gst-Homer 1c to the cytosolic surface of the patch did not activate channels. Addition of GST Homer 1a to the same patch resulted in an activation of $\mathrm{I}_{\min }$ channels.

In a similar series of inside-out recording experiments we used a synthetic peptide in place of GstHomer protein. We found that peptid PPKKFR activates $I_{\text {min }}$, while control peptid PPKKRR has no effect.

By using single-channel patch-clamp recording we discovered that Homer proteins regulate the activity of low-conductance calcium selective store-operated channels $\mathrm{I}_{\min }$ in plasma membrane of A431 cells. Moreover, oligomeric complexes of Homer 1c block the $\mathrm{I}_{\min }$ activity, replacing complexes by Homer 1a isoform leads to activation of $I_{\min }$ channels without agonist stimulation by disruption of protein comlex Homer $1 \mathrm{c}-\mathrm{IP}_{3} \mathrm{R}-\mathrm{I}_{\mathrm{min}}$. Interaction between Homer 1a and former partners of complex Homer $1 \mathrm{c}-\mathrm{IP}_{3} \mathrm{R}-\mathrm{I}_{\min }$ is not critical for the $I_{\min }$ activation, the way of complex disruption is not important for $I_{\min }$ activity. 